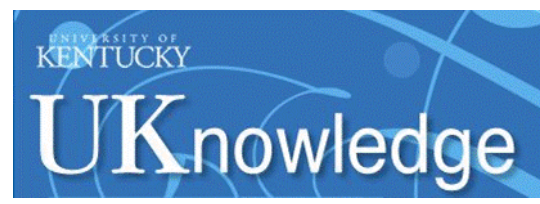

University of Kentucky

UKnowledge

\title{
Impacts of T-Phylloplanin Gene Knockdown and of Helianthus and Datura Phylloplanins on Peronospora tabacina Spore Germination and Disease Potential
}

\author{
Antoaneta B. Kroumova \\ University of Kentucky, amihaylo@uky.edu \\ Ryan W. Shepherd \\ University of California, Berkeley \\ George J. Wagner \\ University of Kentucky, gwagner@uky.edu
}

Follow this and additional works at: https://uknowledge.uky.edu/pss_facpub

Part of the Plant Sciences Commons

Right click to open a feedback form in a new tab to let us know how this document benefits you.

\section{Repository Citation}

Kroumova, Antoaneta B.; Shepherd, Ryan W.; and Wagner, George J., "Impacts of T-Phylloplanin Gene Knockdown and of Helianthus and Datura Phylloplanins on Peronospora tabacina Spore Germination and Disease Potential" (2007). Plant and Soil Sciences Faculty Publications. 63.

https://uknowledge.uky.edu/pss_facpub/63

This Article is brought to you for free and open access by the Plant and Soil Sciences at UKnowledge. It has been accepted for inclusion in Plant and Soil Sciences Faculty Publications by an authorized administrator of UKnowledge. For more information, please contact UKnowledge@lsv.uky.edu. 


\section{Impacts of T-Phylloplanin Gene Knockdown and of Helianthus and Datura Phylloplanins on Peronospora tabacina Spore Germination and Disease Potential}

\section{Digital Object Identifier (DOI)}

https://doi.org/10.1104\%2Fpp.107.097584

\section{Notes/Citation Information}

Published in Plant Physiology, v. 144, no. 4, p. 1843-1851.

(C) 2007, American Society of Plant Biologists

The copyright holder has granted the permission for posting the article here. 


\title{
Impacts of T-Phylloplanin Gene Knockdown and of Helianthus and Datura Phylloplanins on Peronospora tabacina Spore Germination and Disease Potential ${ }^{1[\mathrm{OA}]}$
}

\author{
Antoaneta B. Kroumova, Ryan W. Shepherd, and George J. Wagner* \\ Plant Biology Program, Plant and Soil Sciences Department, University of Kentucky, Lexington, Kentucky \\ 40546 (A.B.K., G.J.W.); and Plant and Microbial Biology Department, University of California, Berkeley, \\ California 94720 (R.W.S.)
}

\begin{abstract}
T-phylloplanin proteins secreted to aerial surfaces of tobacco (Nicotiana tabacum) by short procumbent trichomes inhibit spore germination and blue mold disease caused by the oomycete pathogen Peronospora tabacina. Many other plants were found to contain water-washed leaf surface proteins (phylloplanins), but the functions and properties of these are not known. Here we extend earlier evidence for the antifungal activity of T-phylloplanins using a reverse genetics approach. RNA interference of the T-phylloplanin gene in tobacco 'T.I. 1068' resulted in loss of T-phylloplanin mRNA and protein, loss of in vitro spore germination inhibition activity, and leaf infection inhibition activity of leaf water washes from RNA interference plants, and young knockdown plants were susceptible to disease. The glycoprotein character, adaxial-leaf-surface enrichment of, and renewability of T-phylloplanins are also described. We also report that leaf water washes of sunflower (Helianthus annuus) and jimson weed (Datura metel), but not soybean (Glycine max), like that of tobacco, possess ProteinaseK- and boiling-sensitive $P$. tabacina spore germination and tobacco leaf infection inhibition activities. Results establish that T-phylloplaninins of tobacco are active in P. tabacina inhibition, and indicate that leaf surface proteins of certain non-Nicotiana species that are not susceptible to $P$. tabacina disease can inhibit germination of spores of this oomycete pathogen and inhibit tobacco leaf infection by this pathogen.
\end{abstract}

Aerial surface trichomes, glandular secreting, and nonglandular, nonsecreting types, as well as surfaceaccumulated biochemicals provide a first point of contact, microbial, and insect defense capability for many plants (Wagner et al., 2004). Trichomes and surfaceaccumulated biochemicals, along with the cuticle, are thought to serve as defense components at the phylloplane that together with symbiotic, pathogenic, and commensalistic surface microorganisms constitute a complex and diverse phyllosphere (Andrews and Harris, 2000; Hirano and Upper, 2000; Lindow and Brandl, 2003; Lambais et al., 2006; Leveau, 2006). Secondary compounds accumulated outside the cuticle on plant surfaces (terpenoids, phenylpropanoids, etc.) are generally thought to be exclusively produced by glandular secreting trichomes, but this is established in only a few

\footnotetext{
${ }^{1}$ This work was supported by the Kentucky Tobacco Research and Development Center and the Natural Products Alliance, University of Kentucky. R.W.S. was the recipient of a Jeffrey Graduate Fellowship at the University of Kentucky and a National Science Foundation Postdoctoral Fellowship in microbial biology at the University of California, Berkeley.

* Corresponding author; e-mail gwagner@uky.edu; fax 859-3231077.

The author responsible for distribution of materials integral to the findings presented in this article in accordance with the policy described in the Instructions for Authors (www.plantphysiol.org) is: George J. Wagner (gwagner@uky.edu).

${ }^{[\mathrm{A}]}$ Open Access articles can be viewed online without a subscription

www.plantphysiol.org/cgi/doi/10.1104/pp.107.097584
}

cases (Wagner et al., 2004). However, characterization of trichome exudates obtained by microsampling has shown that many surface-accumulated secondary products are glandular trichome derived. The chemical nature and insect/microbe interactive properties of surface-secreted secondary metabolites have been extensively studied in a number of systems including tomato (Solanum lycopersicum), mint (Mentha piperita), and tobacco (Nicotiana tabacum; Kelsey et al., 1984; Bennett and Wallsgrove, 1994; Jackson and Danehower, 1996; Phillips and Croteau, 1999; Kessler and Baldwin, 2002). In contrast, the occurrence and roles of surfacesecreted proteins in plants are less recognized and studied, despite the fact that antimicrobial surface proteins of animals are well characterized (Zasloff, 1987; Shepherd and Wagner, 2007). More than 500 antimicrobial peptides are formed in animals and many are associated with epithelial surfaces (Zasloff, 2002).

We recently showed that tobaccos synthesize unique proteins, called T-phylloplanins, only in glands of a particular procumbent trichome type (short glandular trichome [SGT]) that apparently do not secrete the well known diterpenes and sugar esters produced and secreted by tall glandular trichomes of tobacco (Shepherd et al., 2005; Shepherd and Wagner, 2007). Evidence that T-phylloplanins are broadly dispersed on the leaf surface comes from experiments that show that water washing of leaves from which trichomes were completely removed (without other apparent damage to the leaf surface) yielded a quantity of T-phylloplanins about equivalent to that washed 
from unaltered leaves (Shepherd et al., 2005). The mechanism of dispersal is unknown, but perhaps SGTsecreted T-phylloplanins are dissolved in copious tall trichome, amphiphilic exudate containing diterpenes and sugar esters that flows from their glands and distributes on the leaf via fissures between adjacent epidermal cell, anticlinal walls (Wagner et al., 2004; Shepherd et al., 2005). T-phylloplanins are composed mainly of hydrophobic and polar amino acids (49\% and $46 \%$ of residues, respectively, as deduced from gene sequence and partial amino acid sequence analysis). They are readily washed from the leaf surface by brief water washing under conditions that remove $<3 \%$ of diterpenes and sugar esters (Shepherd et al., 2005). The T-phylloplanin gene is unique in the gene database, but a number of EST sequences from several widely different plant species share sequence homology and distinct motifs with T-phylloplanin (Shepherd et al., 2005).

T-phylloplanins of tobacco 'T.I. 1068' leaf water wash (LWW) and a truncated recombinant T-phylloplanin protein produced in Escherichia coli inhibit germination of spores of Peronospora tabacina, an oomycete pathogen that causes the potentially devastating blue mold disease in tobaccos (Svircev et al., 1989). Tobacco LWW containing T-phylloplanin was also shown to inhibit disease caused by this obligate biotroph when mixed with spores and applied to leaves of a susceptible tobacco (the assay referred to here as the leaf infection inhibition assay; Shepherd et al., 2005). We also showed earlier that proteolysis of tobacco LWW results in loss of T-phylloplanin protein and P. tabacina spore germination inhibition activity (Shepherd et al., 2005). These results indicate that T-phylloplanin of tobacco 'T.I. 1068' LWW is the active agent of LWW. But, we have been unable to demonstrate that physical removal of only T-phylloplanin from the relatively resistant variety 'T.I. $1068^{\prime}$ renders these plants susceptible to P. tabacina.

RNA interference (RNAi) using short-interfering RNAs has emerged as a major tool in reverse genetics to demonstrate the functionality of genes (Watson et al., 2005). It appears to be very efficient when applied to trichome expressed genes of tobacco. Earlier we observed high RNAi knockdown efficiency in T0 plants for two genes restricted to tall glandular trichomes of tobacco 'T.I. 1068' (approximately $45 \%$ for a P450 oxidoreductase and $64 \%$ for a diterpene cyclase gene; Wang and Wagner, 2003). Here we applied reverse genetics to show that knockdown of the T-phylloplanin gene in tobacco 'T.I. 1068' results in loss of T-phylloplanin mRNA and protein, LWWs of RNAi plants do not inhibit $P$. tabacina spore germination or leaf infection, and young RNAi knockdown plants are susceptible to disease. We also demonstrate here the glycoprotein nature and other properties of T-phylloplanins. And, we show that LWWs from sunflower (Helianthus annuus) and jimson weed (Datura metel), but not from soybean (Glycine max) contain protease- and boiling-sensitive $P$. tabacina spore germination inhibition, and leaf infection inhibition activities.
Figure 1. Knockdown of T-phylloplanins in TO RNAi plants. A, Silver-stained SDS-PAGE showing the presence of T-phylloplanin in LWWs of nontransformed control $\left(20 \mathrm{~cm}^{2}\right.$ asae, adaxial surface area equivalents), and their absence in LWWs of T0 RNAi lines $3,4,5,7,18,21,24,25$, and 26 (60 $\mathrm{cm}^{2}$ asae, each). The left-most lane contains molecular weight standards, and the four T-phylloplanin bands are marked I to IV in the control lane. B, Quantitative PCR analysis (triplicate analysis) showing the comparative expression levels of the control (nontransformed) and the RNAi lines shown in Figure 1A. Arrows indicate unknown proteins of approximately $26 \mathrm{kD}$.

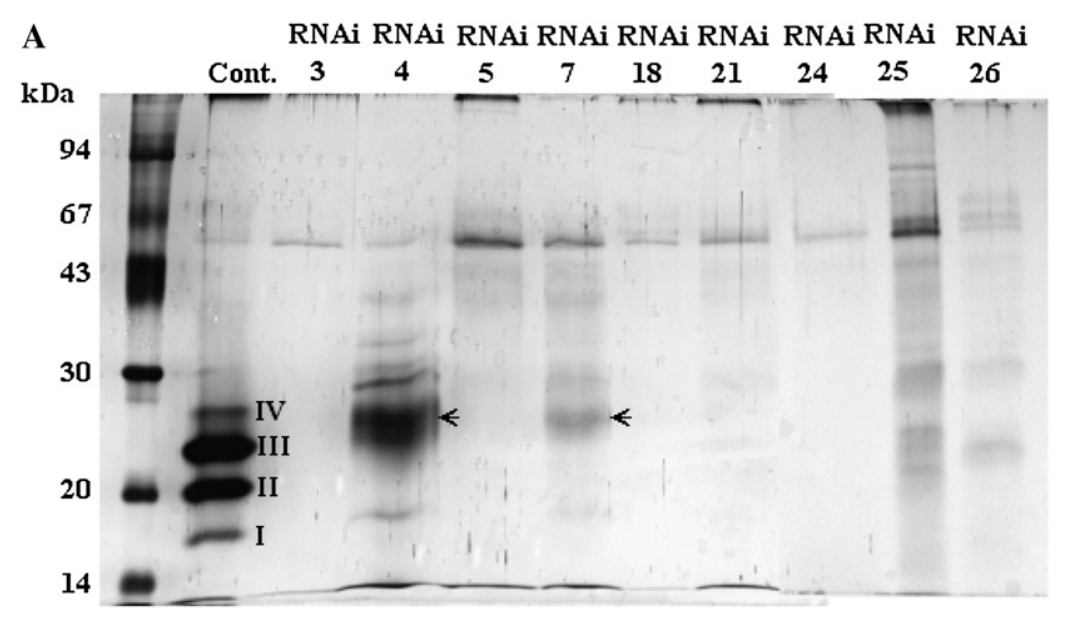

B

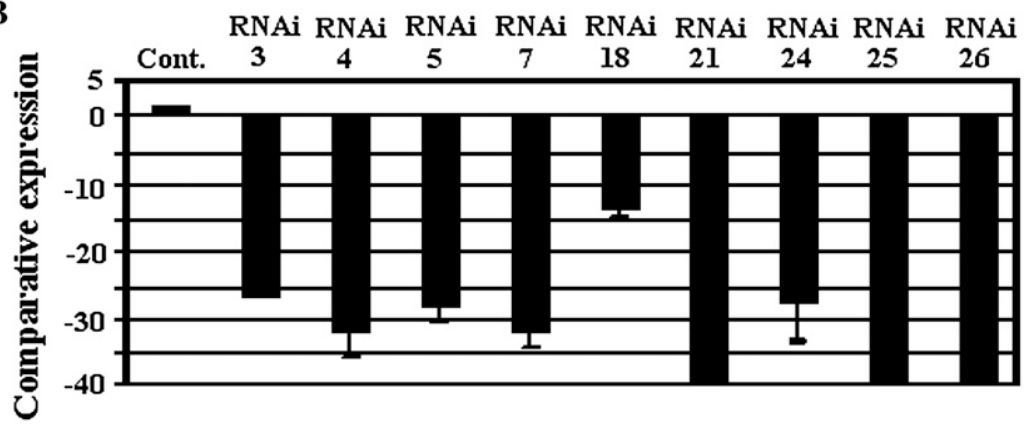




\section{RESULTS AND DISCUSSION}

\section{RNAi Knockdown of T-Phylloplanin}

RNAi is a powerful tool for demonstrating the causal nature of a specific factor suspected of being central to a response (Watson et al., 2005). RNAi knockdown of tobacco 'T.I. 1068' resulted in loss of T-phylloplanin proteins from all 29 primary (T0) transgenic lines tested. Figure 1A shows SDS-PAGE patterns of LWWs prepared from control and nine representative T0 lines. LWWs used represent washes of similar leaves from similar size and age plants. Throughout this work LWWs of different plants were compared on the basis of a standardized leaf adaxial surface area equivalents $\left(\mathrm{cm}^{2}\right.$ asae, for the amount of LWW dry weight recovered from a given area of adaxial surface) because measurable protein (using common protein monitoring methods including the bicinchoninic acid assay) was very low. We consider only the adaxial surface in this standardization because the abaxial surface is shown to contain only approximately one-fifth as much T-phylloplanin as the adaxial surface, see below. As shown in Figure 1A, control LWW gave the typical four band T-phylloplanin pattern, while RNAi lines 3, 4, 5, 7, 18, 21, 24, 25, and 26 lacked T-phylloplanin bands, despite our having used $60 \mathrm{~cm}^{2}$ asae of LWWs versus $20 \mathrm{~cm}^{2}$ asae for control. The nature of the approximately $26 \mathrm{kD}$ band(s) in RNAi lines 4 and 7 (arrows) is unknown. In any case, the banding patterns of these two lines were not typical of control LWW. Further study is needed to clarify this observation. Figure 1B shows the expression of the T-phylloplanin gene (as determined using quantitative PCR) in control and the RNAi lines shown in Figure 1A. The degree of knockdown varied among T0 lines, but all were greatly reduced. The apparent knockdown of all 29 RNAi plants tested may be due to the stability of RNAi in T0 populations, the nonessential nature of the T-phylloplanin gene, and/or the uniqueness of this gene.

LWWs from knockdown plants were assessed for their ability to inhibit $P$. tabacina spore germination using an in vitro microscope slide germination assay (Shepherd et al., 2005). As shown in Figure 2, control (nontransformed) tobacco and vector control (pBIMC, lacking the RNAi construct) caused $100 \%$ inhibition at 1.0 and $2.0 \mathrm{~cm}^{2}$ asae of LWW, while lower levels $(0.48$ and $0.24 \mathrm{~cm}^{2}$ asae [later not shown]) caused only low inhibition in all cases. In contrast, LWWs from all RNAi lines showed low water control-like activity. All samples used for in vitro spore germination tests were used for leaf infection inhibition assays employing essentially the method described earlier (Shepherd et al., 2005). Correlation between spore germination inhibition and leaf infection inhibition (- notation signifying no disease, and + signifying disease development, see below the $x$ axis) was observed for most samples. We observed some variability in results of leaf infection

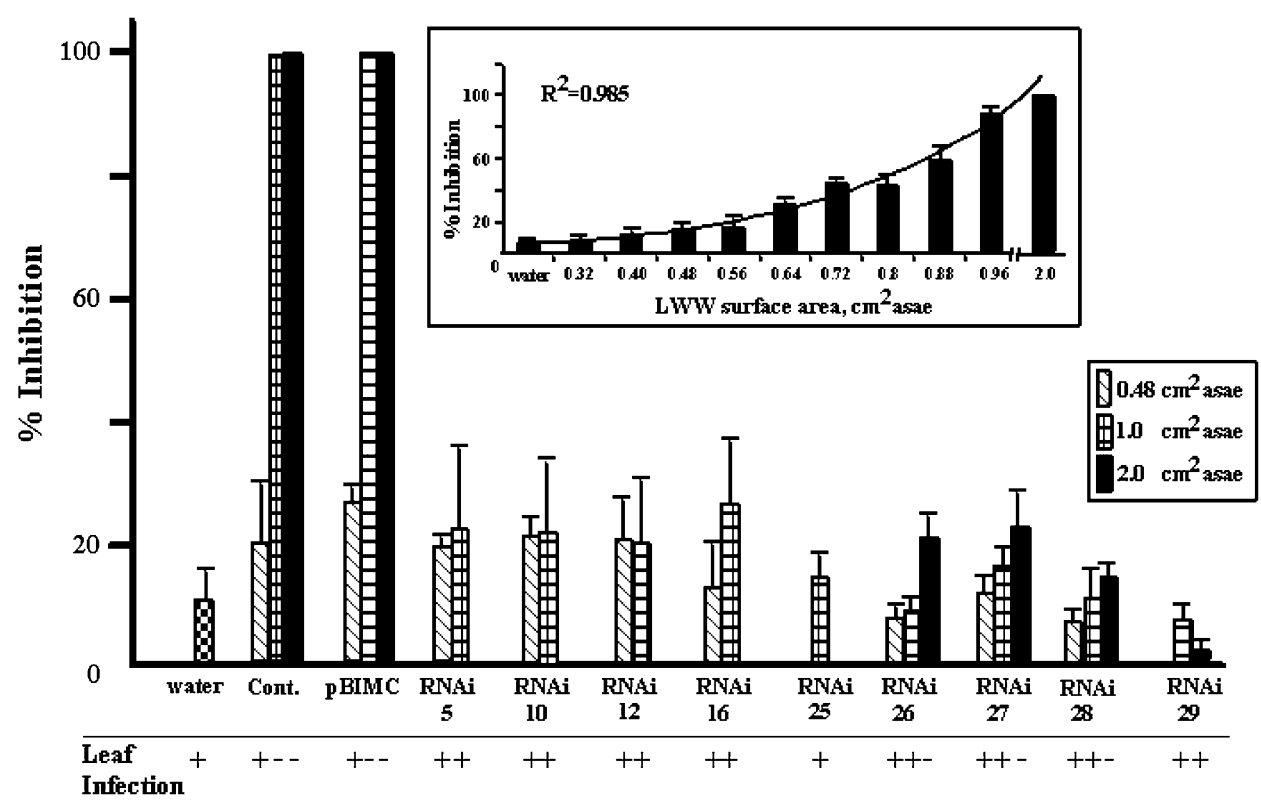

Figure 2. Inhibition of $P$. tabacina spore germination and leaf infection by LWWs of water and empty vector controls versus RNAi T0 plants. Samples of LWWs from the surface equivalents denoted were mixed with spores and applied to glass slides (in triplicate) to monitor germination (e.g. $0.48 \mathrm{~cm}^{2}$ asae/400 spores is the lowest concentration tested). Means are the average of three independent experiments. Water (no LWW), nontransformed control, and empty vector control (pBIMC) LWWs (bar graph sets from the left; first, second, third, respectively) and TO RNAi lines 5, 10, 12, 16, and 25 through 29 are shown. Results of $P$. tabacina leaf infection inhibition assays on susceptible tobacco ' $Y 14^{\prime}$ ' are shown below the $x$ axis as + , designating disease occurrence, and -, designating lack of disease. Inset: Titration of spore germination inhibition activity versus surface equivalents of LWW from nontransformed tobacco. 
assays with some RNAi lines when $2.0 \mathrm{~cm}^{2}$ asae was tested. This may be due to higher diterpene contamination of LWW due to LWW dose. But, we repeat, LWWs of all RNAi lines lacked phylloplanin proteins upon SDS-PAGE analysis (Fig. 1; data not shown). Figure 3A illustrates the typical result of a leaf infection inhibition assay. In this example LWW from RNAi line 5 was mixed with spores and applied as five spots onto the adaxial surface of the upper half of the leaf shown. Control plant LWW was applied with spores as five spots onto the lower half. Infection occurred at all spots with LWWs from the RNAi plant lacking T-phylloplanins, and no infection occurred where control LWW was applied. Thus, reverse genetics experiments leading to data of Figures 1, 2, and $3 \mathrm{~A}$ are consistent with the conclusion that T-phylloplanins of tobacco are responsible for the ability of control tobacco LWW to inhibit $P$. tabacina disease. These results support earlier data that showed that a truncated recombinant T-phylloplanin inhibits P. tabacina spore germination, that ProteinaseK treatment of LWW results in loss of this activity and T-phylloplanin proteins, and that spore germination inhibition and leaf infection inhibition show similar LWW protein concentration dependence (Shepherd et al., 2005). Mature and midage RNAi plants were resistant to $P$. tabacina though LWWs from these plants did not inhibit spore germination in vitro or prevent leaf infection. We suggest that this is due to the continued presence of high levels of tall-trichome-produced diterpenes that are shown to inhibit $P$. tabacina disease when present in high levels, as found on midmaturity and mature tobacco 'T.I. 1068' leaves (Jackson and Danehower, 1996). When seedlings (five leaf stage) of RNAi plants were tested we found these to be susceptible, presumably because diterpene levels were approximately $20 \%$ of that of mature leaves. As illustrated in Figure 3, B and C, disease occurred on young RNAi plants of this normally resistant tobacco variety. Thus, we suggest that tobacco has two surfacedisposed mechanisms for inhibiting $P$. tabacina disease, SGT-produced T-phylloplanins, and, on older leaves, tall-trichome-produced, abundant diterpenes (known to provide resistance to $P$. tabacina, when abundant, see Shepherd et al., 2005) plus T-phylloplanins.

The apparent nonlinearity in spore germination inhibition activity of control and vector control (pBIMC) shown in Figure 2 suggested that a threshold level of T-phylloplanin was required for activity. To elaborate on this observation we examined concentration dependence more thoroughly. As shown in the inset of Figure 2, nonlinear concentration dependence was found, with an apparent threshold of approximately $1.0 \mathrm{~cm}^{2}$ asae. We speculate that this may suggest a mechanism in which a certain level of T-phylloplanin/ spore wall or plasma membrane aggregate is required to affect the spore so as to inhibit germination. Since spores used in our studies were thoroughly washed to remove an intrinsic inhibitor (Svircev et al., 1989), it is unlikely that T-phylloplanin interacts with this un-
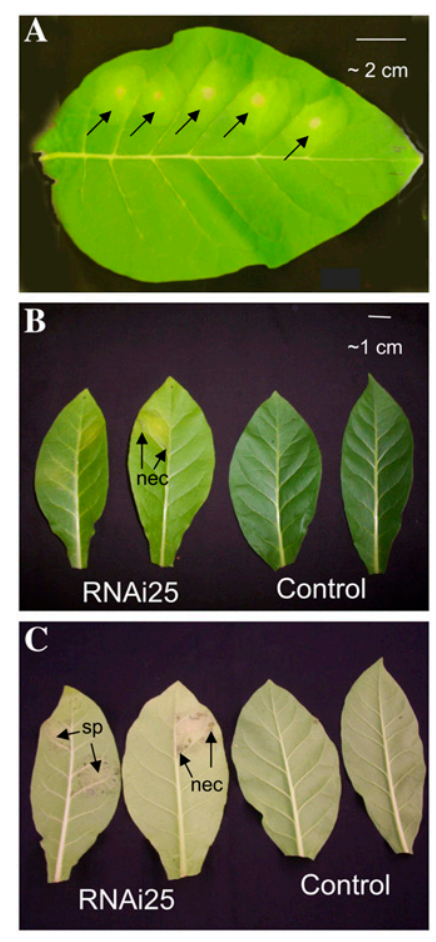

Figure 3. P. tabacina leaf infection inhibition assays. A, Standard assay of LWWs on attached leaves of the five leaf stage, susceptible tobacco 'KY14'. Spores were mixed with a LWW and applied to a leaf in five separate $4 \mu \mathrm{L}$ drops. Each spot represents $1 \mathrm{~cm}^{2}$ asae of LWW and 400 spores giving a spot area of approximately 1 to $1.5 \mathrm{~cm}^{2}$. In the example shown, LWW of RNAi line 5 was applied to the adaxial surface, at the regions indicated with arrows, to the upper leaf half, and control LWW was applied similarly to the lower leaf half. After $5 \mathrm{~d}$ lesions were evident on the top half of leaves. B, Leaf infection inhibition assay on attached leaves of young (five leaf stage) tobacco 'T.I. 1068', RNAi line 25 , versus control. The figure shows the adaxial surfaces of two RNAi plant and two control plant leaves inoculated with $P$. tabacina spores, detached and photographed $7 \mathrm{~d}$ later. Chlorosis and early necrosis (nec) is evident on leaves from this (RNAi line 25) and other RNAi lines (data not shown), particularly near the tip. These same leaves were placed in plastic bags and in the dark to induce sporulation. After $12 \mathrm{~h}$ gray, sporulating spots (sp) were visible on the abaxial epidermis, as is typical of this disease, and necrotic areas (nec) became more prominent (Fig. 3C).

characterized, but recognized entity. The spore wall structure and details of the germination process in $P$. tabacina and the mechanism of spore germination inhibition by T-phylloplanin are not understood.

We have found that most broadleaf plants examined possess phylloplanins (LWW proteins, as demonstrated by SDS-PAGE), but their abundances and polypeptide profiles vary greatly (Shepherd et al., 2005; R.W. Shepherd and G.J. Wagner, unpublished data). Earlier we showed that tobacco, sunflower, and soybean have very high, moderate, and low levels of phylloplanins, respectively, based on SDS-PAGE of similar surface area equivalents of LWWs (Shepherd et al., 2005). Here we compared the ability of LWWs from these plants and from jimson weed (moderate-to-high phylloplanin level) to inhibit $P$. tabacina spore germination and leaf infection. 


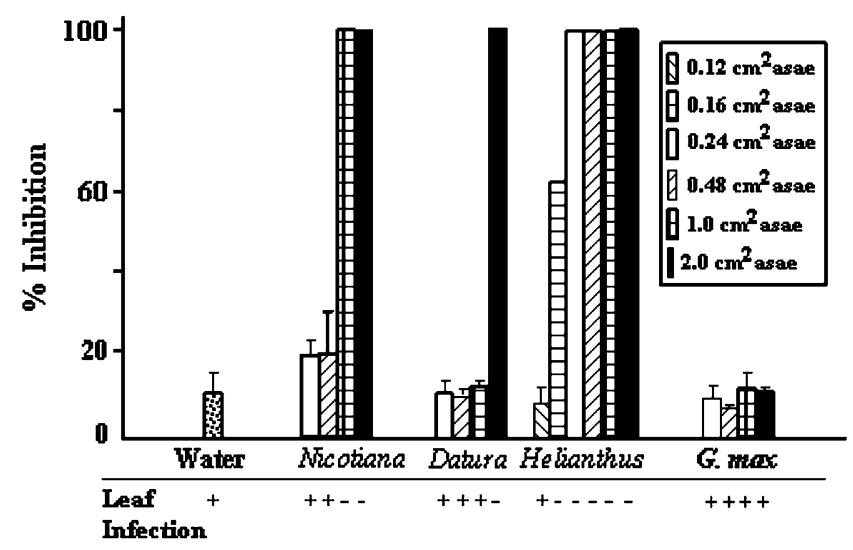

Figure 4. Relative inhibition of $P$. tabacina spore germination and leaf infection by tobacco, jimson weed, sunflower, and soybean phylloplanins at different LWW concentrations. Results of leaf infection inhibition assays on susceptible tobacco 'KY14' are shown below the $x$ axis as + designating disease occurrence and - designating lack of disease.

Figure 4 shows the relative spore germination inhibition activities of water control, tobacco, jimson weed (both of the family Solanaceae), sunflower (Asteraceae), and soybean (Fabaceae). As shown, the relative activities, based on surface area, are: sunflower $>$ tobacco $>$ jimson weed. Soybean LWW showed no activity at the surface area equivalent used. Soybean, Zea mays, and Vitis vinifera, like soybean, appear to have low levels of, or no phylloplanins, while most broadleaf plants tested do (R.W. Shepherd and G.J. Wagner, unpublished data). There appeared to be a threshold concentration effect with tobacco, sunflower, and jimson weed LWWs. The same preparations used to assess spore germination activity in Figure 4 were used for leaf infection inhibition assays. Results were consistent with those of spore germination assays, as shown at the bottom of the figure. The observation that sunflower LWW inhibited P. tabacina spore germination, indeed with higher activity per $\mathrm{cm}^{2}$ asae than tobacco or jimson weed LWWs, was particularly interesting because this plant is of a different plant family than tobacco and jimson weed, and P. tabacina is reported to be host specific to Nicotiana species (Svircev et al., 1989). We speculate that presence of phylloplanins that inhibit P. tabacina on sunflower and jimson weed may be components of innate resistance to $P$. tabacina (and perhaps related pathogens) in these plants, or, phylloplanins on these plants affect other pathogens, perhaps using a similar mechanism. We note that attempts to infect sunflower and jimson weed leaves by applying $P$. tabacina spores (100-300 spores $/ \mu \mathrm{L}$ ) resulted in no disease (data not shown).

We determined if LWW proteins of sunflower and jimson weed, like T-phylloplanins of tobacco, were sensitive to proteolysis. As shown in Figure 5, treatment with insoluble ProteinaseK resulted in the loss of major LWW polypeptides in each case. As in inhibition activity experiments shown in Figure 2, all samples represent the same LWW surface area equivalent (15 $\mathrm{cm}^{2}$ asae). Note that polypeptide profiles of tobacco, sunflower, jimson weed, and soybean phylloplanins (Fig. 5, lanes 3, 5, 7, and 9, respectively) are different. Double bands at approximately $67 \mathrm{kD}$ in lanes 3 to 9 are electrophoresis artifacts common to all samples. Boiling of samples to precipitate proteins also resulted in loss of soluble phylloplanins (data not shown). We tested the effects of ProteinaseK treatment and boiling of sunflower and jimson weed LWWs in P. tabacina spore germination and leaf infection assays (Fig. 6). Surface area equivalents were adjusted to provide for the minimum concentration needed to cause $100 \%$ inhibition with untreated LWW. As shown, proteolysis and boiling destroyed inhibitions, suggesting that phylloplanins are responsible for the activities. In our previous work (Shepherd et al., 2005), we showed that proteolysis of tobacco LWW resulted in loss of spore germination inhibition activity. Here we extend that observation to include loss of leaf infection inhibition activity with tobacco, sunflower, and jimson weed LWWs. Trichome exudate of sunflower contains sesquiterpenes and diterpenes (Spring et al., 1992) that might be responsible for P. tabacina inhibition activities shown. However, these are not thought to be localized on the leaf surface and therefore it is unlikely they would be extracted by brief water washing. And, it is highly unlikely that they would be impacted by ProteinaseK treatment. Similarly, trichome exudate acyl sugars of Datura species, which are shown to have insect interactive properties (Hare, 2005), are not likely impacted by ProteinaseK. To verify the correlations found here between protease- and boiling-sensitive phylloplanins and $P$. tabacina inhibition activities, the genes for sunflower and jimson weed must be isolated, recombinant protein prepared, and tested, and RNAi used to demonstrate a causal role of these phylloplanins, as has been done with T-phylloplanin (Shepherd et al., 2005 , and here). We note that an unannotated EST from sunflower (HaCD847345) having significant homology to the T-phylloplanin gene has been reported (Shepherd et al., 2005).

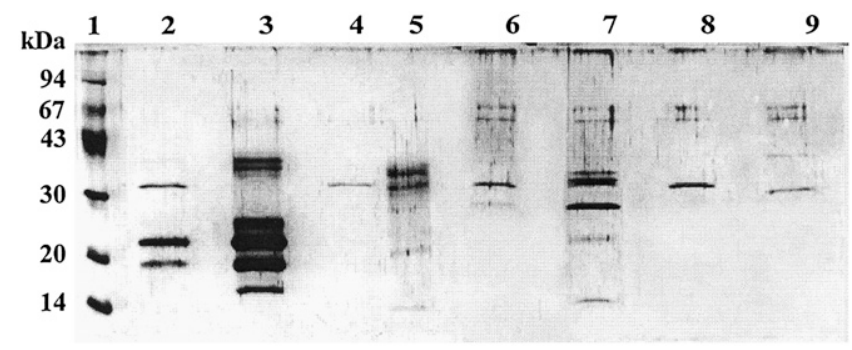

Figure 5. Protease sensitivity of tobacco, jimson weed, sunflower, and soybean phylloplanins. Lane 1 contains $M_{\mathrm{r}}$ markers. Lanes 2 and 3, tobacco LWW, + and - ProteinaseK, respectively; lanes 4 and 5, sunflower LWW, + and - ProteinaseK, respectively; lanes 6 and 7, jimson weed LWW, + and - ProteinaseK, respectively; lanes 8 and 9, soybean LWW, + and - ProteinaseK, respectively. Protein bands at approximately $32 \mathrm{kD}$ in lanes 2, 4, 6, and 8 are soluble ProteinaseK released during digestions. All samples contained $15 \mathrm{~cm}^{2}$ asae of LWW. 


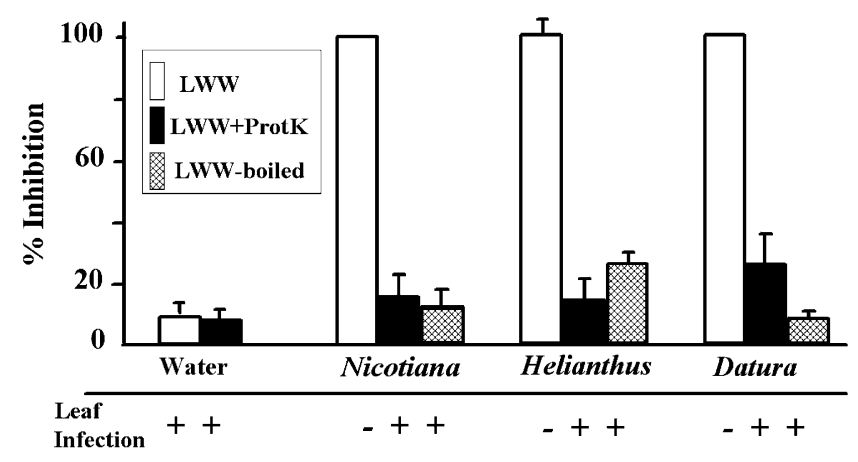

Figure 6. Influence of ProteinaseK digestion and boiling on P. tabacina spore germination inhibition and leaf infection inhibition by tobacco, sunflower, and jimson weed LWWs. Concentrations of tobacco $\left(1 \mathrm{~cm}^{2}\right.$ asae), sunflower $\left(0.2 \mathrm{~cm}^{2}\right.$ asae), and jimson seed $\left(6 \mathrm{~cm}^{2}\right.$ asae) were adjusted to provide maximum inhibition of spore germination in the absence of ProteinaseK. Results of leaf inhibition assays are shown below the $x$ axis as + designating disease occurrence and - designating lack of disease.

\section{Characteristics of T-Phylloplanin}

Genetic evidence indicates that the T-phylloplanin gene produces one protein, but four bands are found after SDS-PAGE of tobacco LWW. All amino acid sequences recovered from T-phylloplanin bands I to IV are present in the protein sequence of the T-phylloplanin gene, representing $54 \%$ of the open reading frame (Shepherd et al., 2005). The predicted molecular mass of a protein encoded by the T-phylloplanin gene is $13 \mathrm{kD}$, and the smallest band (band I, Fig. 1A) found by SDS-PAGE is approximately $16 \mathrm{kD}$. Bands II, III, and IV $(19,21$, and $25 \mathrm{kD}$, respectively) do not appear to be multiples of $13 \mathrm{kD}$. A truncated, recombinant T-phylloplanin that inhibits $P$. tabacina spore germination is approximately $11 \mathrm{kD}$ (Shepherd et al., 2005). These results suggest the possibility of posttranslational modification to yield all four bands. Ser and Asn each account for $14 \%$ of T-phylloplanin amino acid residues, and thus there is much potential for glycosylation. And, most secreted proteins of eucaryotes are glycoproteins. We applied sensitive Schiff staining to tobacco LWW after SDS-PAGE. As shown, T-phylloplanin bands were highly stained (Fig. 7A) and the control staining procedure used to distinguish nonspecific background staining (periodic oxidation is omitted) clearly reduced staining of T-phylloplanin bands and glycosylated protein standards, but not nonglycosylated standards (Fig. 7B). Protein profiles before and after glycoprotein staining were identical (data not shown). We attempted to use bacteria-derived O-glycosidase, EC 3.2.1.97, and $N$-glycosidase A, EC 3.5.1.52, to cleave carbohydrate, but these enzymes, which have specific carbohydrate/ protein linkage requirements, had no impact. Attempts to chemically deglycosylate using trifluromethanesulphonic acid resulted in loss of Schiff stain, but proteins were apparently degraded. Results of Schiff staining suggest that the multiplicity of T-phylloplanins may be due to differential glycosylation and are consistent with earlier data indicating the occurrence of one T-phylloplanin gene and one protein product (Shepherd et al., 2005). However, other possibilities may explain the band multiplicity (e.g. posttranslational modification of the $C$ terminus). We note that differences between the total composition of amino acids (those stable to acid hydrolysis) of bands II and III were found to be small (approximately 10\%, data not shown). Understanding the nature of and role of sugar substitution in T-phylloplanins requires further study. But, we speculate that the highly glycosylated, highly hydrophobic protein nature of T-phylloplanin may assist its solution in amphoteric, copious, tall-trichome-secreted diterpenes and sugar esters, and facilitate its wide dispersal on the leaf surface. We note that sunflower and jimson weed phylloplanins also appear to be glycosylated (data not shown). And, both species possess small trichomes (data not shown), somewhat similar in morphology (short, procumbent) to SGTs that produce T-phylloplanins. Soybean and Z. mays appear to lack this type of trichome.

Since airborne $P$. tabacina spores are the source of blue mold disease and disease is known to generally initiate on the adaxial (upper) surface (Svircev et al., 1989), one expects that adaxial leaf surfaces might be enriched in T-phylloplanins, above that found on the abaxial surface. We determined the relative distribution of T-phylloplanins on the upper (adaxial) and lower (abaxial) surfaces of single leaves and found that the former had substantially more proteins than the latter (Fig. 8, A and B, respectively). It is difficult to

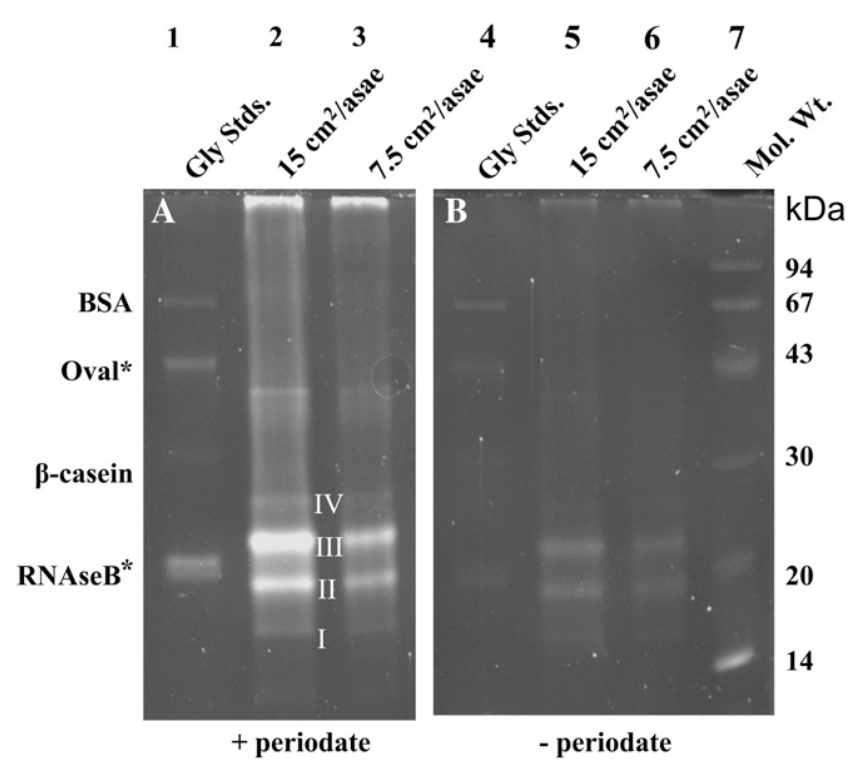

Figure 7. The glycoprotein nature of T-phylloplanins. A, Glycoprotein staining after reaction in the presence of periodate: lane 1, standard proteins (ovalbumin and RNAseB, glycosylated [asterisks], and BSA and $\beta$-casein, not glycosylated); lanes 2 and 3, T-phylloplanin (15 and $7.5 \mathrm{~cm}^{2}$ asae, respectively). B, Glycoprotein staining after reaction without periodate: lane 1, standard proteins; lanes 2 and 3, T-phylloplanin (15 and $7.5 \mathrm{~cm}^{2}$ asae, respectively); lane $4, M_{\mathrm{r}}$ markers. 

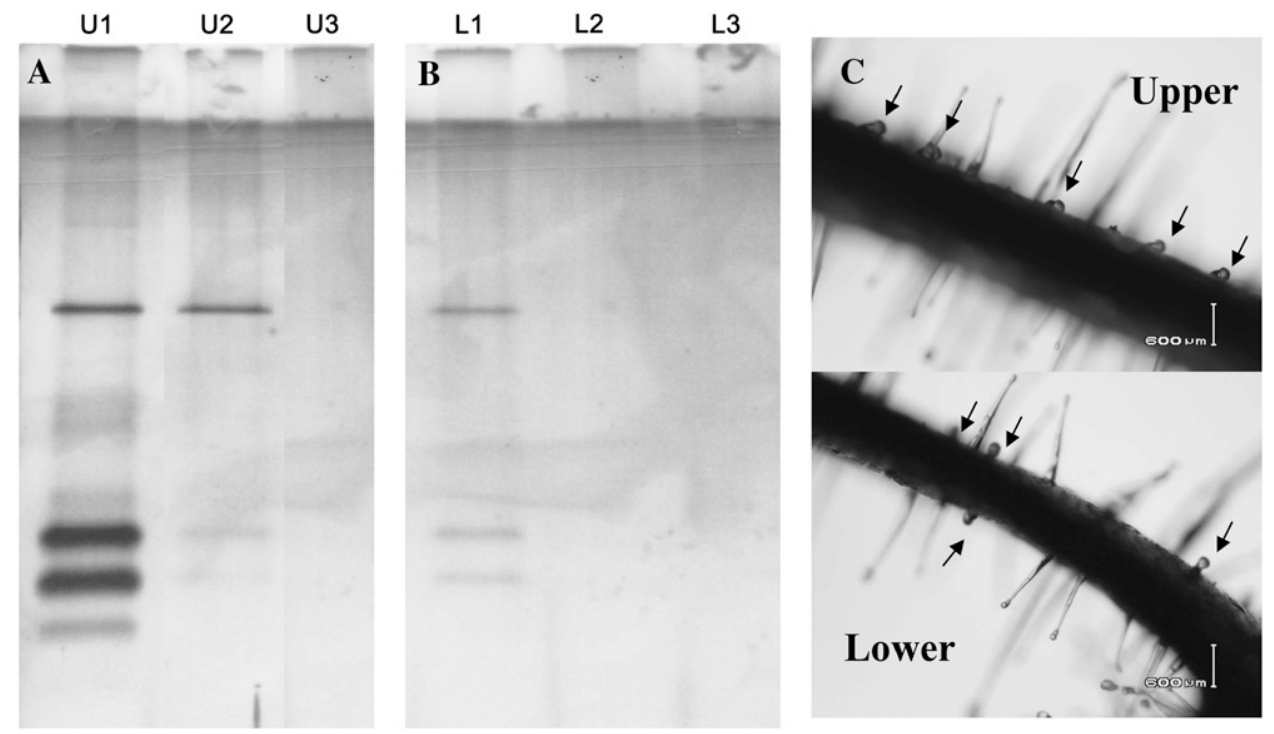

Figure 8. Distribution of T-phylloplanins and SGTs on adaxial (upper) and abaxial (lower) leaf surfaces of tobacco. A, Sequential series of three $20 \mathrm{~s}$ LWWs (U1, U2, U3, respectively) of the adaxial surface of a mature leaf. B, Three similar washes of the abaxial surface of the same leaf (L1, L2, L3, respectively). C, Two cross-sectional views of a mature leaf showing the relative enrichment of SGTs (arrows) on the adaxial versus abaxial surfaces.

quantitatively determine the distribution of short procumbent trichomes on entire leaf surfaces. However, light microscope observations of leaf cross sections clearly indicate an enrichment of at least 4- to 5-fold of these trichomes on the upper surface (Fig. 8C). Thus, there is a correlation between T-phylloplanin enrichment on the upper leaf surface, enrichment on this surface in the numbers of the trichome type shown to produce them, and the airborne nature/directionality of $P$. tabacina spore deposition onto the leaf.

To assess if T-phylloplanins were renewed after water washing to remove all protein (to perhaps mimic removal by rain), we thoroughly washed a group of size/age/leaf number matched, mature leaves (attached to the plants), then rewashed individual leafposition-matched mature leaves on days $7,11,16$, and 21. As shown in Figure 9, protein was renewed, but total leaf protein appeared to decline after $11 \mathrm{~d}$, perhaps suggesting reduced synthesis as leaves age. A water wash made approximately $3 \mathrm{~h}$ after the initial one on day 0 showed only traces of bands II and III (data not shown). We also found that young leaves and auxiliary-bud leaves produce more T-phylloplanins than old leaves (data not shown), and we note that not all T-phylloplanin is washed from field plants after a strong rain (data not shown). Results of the above experiments are consistent with the positioning and renewability of T-phylloplanins to serve as a firstpoint-of-contact defense against $P$. tabacina disease in plants growing in a natural environment. Further study is needed to define, in detail, phylloplanin synthesis and renew ability at different stages of leaf development.

\section{Summary}

The reverse genetics approach confirming a correlation between an effecter gene product and a disease is a powerful tool in understanding the role of plant defenses against pathogens. Here we show that RNAi knockdown of the T-phylloplanin gene results in loss of T-phylloplanin mRNA, proteins, P. tabacina spore germination inhibition, and leaf infection inhibition activities of LWW, and renders young RNAi plants susceptible to disease. These findings confirm earlier results of studies using T-phylloplanin-containing LWWs

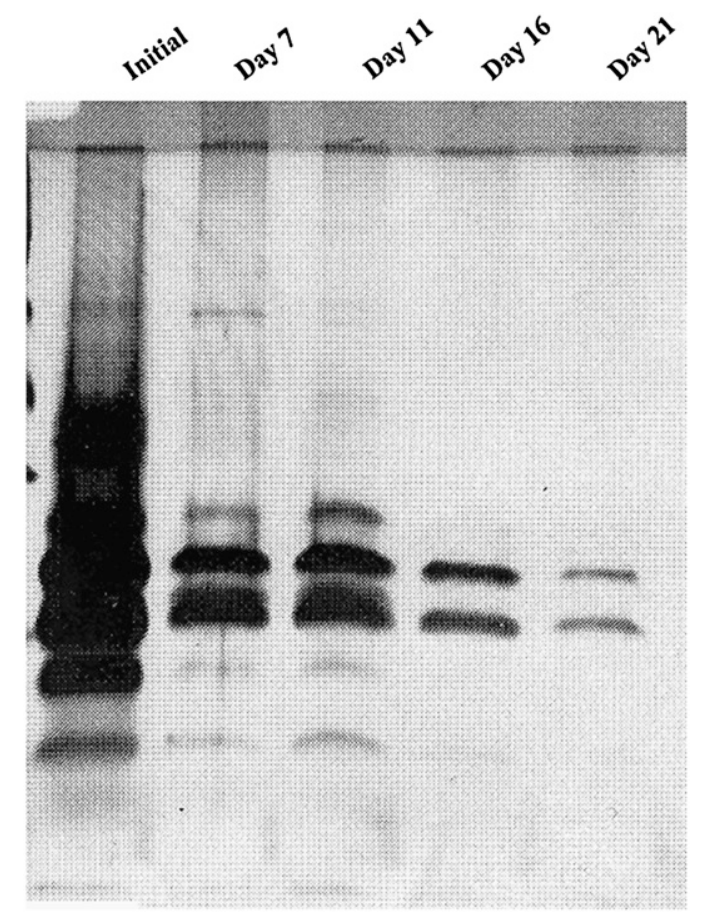

Figure 9. Renewability of leaf T-phylloplanins after water washing. Plants were water washed and then matched leaves were rewashed after 7, 11, 16, and $21 \mathrm{~d}$. LWWs were lyophilized and examined by SDS-PAGE, along with an initial (day 0) LWW. 
of wild-type plants that showed a correlation between the presence of T-phylloplanin and P. tabacina spore germination. We also addressed here the enigma presented by the evidence for one apparent T-phylloplanin gene, but four T-phylloplanin polypeptides (apparently having the same amino acid sequence) on SDS-PAGE by discovering the glycoprotein nature of the polypeptides. Several aspects of T-phylloplanins that relate to the biology of their surface disposed nature and the airborne path to spore deposition in $P$. tabacina infection were studied. We found enrichment of T-phylloplanins on the adaxial leaf surface, which correlates with adaxial enrichment in SGTs producing them, and with the airborne route of spore contact with the leaf. We also show that T-phylloplanins are renewable after water washing, a correlation that supports adaptability of a T-phylloplaninbased defense component to growth in a natural environment that includes occasional washing of leaves by rain or dew. Finally, a most interesting finding is that LWW of sunflower bears a protease-sensitive surface component (phylloplanin) that inhibits $P$. tabacina spore germination and leaf infection. This was unexpected because sunflower (order Asterales) is not closely related to plants of the order Solanales (tobacco, jimson weed), and is not known (or found here) to be susceptible to the highly selective pathogen, $P$. tabacina (Svircev et al., 1989). The characteristics of sunflower (and jimson weed) phylloplanins and their genes, and their possible impacts on pathogens of these plants remain to be researched. Understanding whether the activity of sunflower phylloplanins against $P$. tabacina reflects a common mechanistic property of certain phylloplanins of unrelated species, a coevolutionary remnant, or another property remains to be determined.

\section{MATERIALS AND METHODS}

\section{Plant Materials and LWW Collections and Protein Characterization}

Experimental tobacco (Nicotiana tabacum) 'T.I. 1068', sunflower (Heilanthus annuus) 'Dove Hybrid', jimson weed (Datura metel), and soybean (Glycine max) var. Hardsoy were grown in the greenhouse under natural light at $22^{\circ} \mathrm{C}$ to $24^{\circ} \mathrm{C}$ with weekly fertilization with 20:20:20 NPK, primarily between September and July. To determine leaf area, leaves were traced onto uniform-weight paper and areas were determined by weighing tracings. LWWs, obtained by washing leaves in distilled water for $20 \mathrm{~s}$ with gentle agitation, were lyophilized, resuspended in distilled water, and centrifuged at $12,000 \mathrm{~g}$ for $5 \mathrm{~min}$ before supernatants were used. Quantification of LWWs was made on the basis of leaf surface area from which they were obtained (assuming most phylloplanin to be in the adaxial surface) because standard protein assays using the Bio-Rad (Bio-Rad Laboratories) and bicinchoninic acid (Pierce Chemical Company) did not provide reliable results, or protein levels were too low (for RNAi plants). LWW quantity is described as $\mathrm{cm}^{2}$ asae. SDS-12\% Glycine-PAGE and silver staining was as previously described (Shepherd et al., 2005). The glycoprotein nature of phylloplanins was assessed using the Glyco-Profile III, fluorescent glycoprotein detection kit (Sigma-Aldrich). Glycosylation indicator controls included the use of the relatively highly glycosylated proteins ovalbumin and RNAseB and bovine serum albumin and $\beta$-casein, proteins lacking glycosylation. And parallel experiments were made with and without periodic acid reagent. To assess distribution of T-phylloplanins on the adaxial versus abaxial surfaces, leaves were gently sprayed with distilled water using a fine airbrush sprayer, first the adaxial surface then the abaxial surface. Three consecutive sprayings were made of each surface were collected separately, lypholyzed, and analyzed.

\section{RNAi Constructs and Plant Transformation}

The RNAi construct consisted of S-PhyllP (sense oriented) and AS-PhyllP (antisense oriented) T-phylloplanin sequences, minus the stop codon (bases 46495 of T-phylloplanin mRNA), joined by a linker so that dsRNA molecules with hairpin single-stranded loops would be formed after transcription. The linker region was generated by treating the GUS gene in pBI121 with EcoRV and religating the blunt ends to make dGUS containing a 230 bp deletion. S-PhyllP and AS-PhyllP were PCR amplified from 'T.I. 1068' total cDNA using primers that incorporated different restriction sites (S-PhyllP sense, XbaI, 5' -AGCTTCTAGAATGGCTTCAGCAAAAATTTTC-3'; S-PhyllP antisense, PstI, 5'-AGCTCTGCAGATTGATGTTAAGATTAAGTA-3' ; AS-PhyllP sense, SstI, 5' -AGCTGAGCTCATGGCTTCAGCAAAAATTTTC-3'; AS-PhyllP antisense, XhoI, $5^{\prime}$-AGCTCTCGAGATTGATGTTAAGATTAAGTA-3'). The dGUS gene was PCR amplified using primers that incorporated PstI and XhoI sites (dGUS sense, 5' -AGCTCTGCAGATGTTACGTCCTGTAGATACCCCA-3'; dGUS antisense, $5^{\prime}$-AGCTCTCGAGTCATTGTTTGCCTCCCTGCT-3'). All PCR products were cloned into the vector pGem-T (Promega) for genetic manipulations using conventional molecular cloning techniques. The final construct, PhyllPRNAi (consisting of XbaI-S-PhyllP-PstI/PstI-dGUS-XhoI/XhoI-AS-PhyllP-SstI), was cloned into the plant transformation vector $\mathrm{pBI} 121$ that had been treated with XbaI and SstI. The transformation of this construct into Agrobacterium tumefaciens GV3101 and subsequent introduction into tobacco 'T.I. 1068' were as described earlier (Shepherd et al., 2005).

\section{Quantitative PCR}

Total RNA was isolated from the leaves of control and RNAi plants using RNeasy Plant mini kit (Qiagen). RNA purity was evaluated by monitoring $\mathrm{OD} 260 / \mathrm{OD} 280 \mathrm{~nm}$ ratio $(\geq 1.9)$. Reverse transcription reactions were performed with $2 \mu \mathrm{g}$ RNA and oligo dT primers, using the Omniscript reverse transcription kit (Qiagen). Phylloplanin primers for the real-time PCR were selected within the T-phylloplanin cDNA (GenBank accession Nt AY705384). The forward and reverse primers were 5' -GCTGCATTTGCCATACTTGTT-3' and 5' -GCTCCCGATCCATTTGTTATT-3', respectively. Primers for the tubulin gene (normalization standard) were: forward, 5'-ATGAGAGAGTGCATATGCAT-3'; reverse, 5'-TTCACTGAAGAAGGTGTTGAA. The reactions contained: $10 \mu \mathrm{L}$ iTaq SYBR Green supermix with ROX (Bio-Rad Labs), $500 \mathrm{~nm}$ of each primer, $1 \mu \mathrm{L}$ cDNA template from the reverse transcription reaction, and water, to make a final volume to $20 \mu \mathrm{L}$. Reactions containing T-Phylloplanin primers and tubulin primers were otherwise identical. The reaction mixtures were assembled in low profile tubes (MJ Research). The run protocol was: denaturing $-94^{\circ} \mathrm{C}$ for $5 \mathrm{~min}$; amplification, repeated 36 times $\left(94^{\circ} \mathrm{C}\right.$ for $45 \mathrm{~s}, 53^{\circ} \mathrm{C}$ for $45 \mathrm{~s}, 72^{\circ} \mathrm{C}$ for $2 \mathrm{~min}$ ), final extension at $72^{\circ} \mathrm{C}$ for $7 \mathrm{~min}$, and cooling to $10^{\circ} \mathrm{C}$. Real-time PCR and fluorescence detection were executed with the DNA Engine Opticon2 system (MJ Research).

To quantify the relative amounts of T-phylloplanin message we applied the $\Delta \Delta$ method (ratio $=2^{-\Delta \Delta C P}$ ) developed by PE Applied Biosystems (Perkin Elmer; Pfaffl, 2001). All real-time PCR experiments were repeated three times.

\section{Spore Germination and Leaf Infection Inhibition Assays}

Assays were essentially as described earlier (Shepherd et al., 2005), but using 400 spores $/ 4 \mu \mathrm{L}$ in both assays.

P. tabacina susceptible tobacco 'KY14' was used for leaf infection inhibition assays testing RNAi and control plant LWWs. Where RNAi plants were tested for disease susceptibility, 400 spores $/ 4 \mu \mathrm{L}$ were spotted on leaves, and these analyzed as described in the legend of Figure 3.

\section{ProteinaseK Digestions}

Protease digestion of LWWs was made essentially as previously described (Shepherd et al., 2005), but with several modifications. Insoluble ProteinaseK affixed to acrylic beads (no. P0803, $50 \mathrm{mg}$, Sigma-Aldrich) was placed in a 1.5 $\mathrm{mL}$ Eppendorf tube with sterile deionized water, and washed three times, with centrifugation at 2,600g. Samples in $80 \mu \mathrm{L}$ water were gently mixed with 
beads and incubated for $2 \mathrm{~h}$ at $37^{\circ} \mathrm{C}$. Tubes were centrifuged at 2,600g and supernatants used for assays. To inactivate by boiling, samples were boiled for $10 \mathrm{~min}$ and centrifuged at $10,000 \mathrm{~g}$ for $10 \mathrm{~min}$.

\section{Accession Number}

The GenBank accession number of the T-phylloplanin gene is AY705384.

\section{ACKNOWLEDGMENTS}

We thank Dr. Sitakanta Pattanaik for contributing tobacco-specific tubulin primers, Brian King for maintaining plants, Ruth Babbett for preparing P. tabacina spores, and Lloyd Asher for help with experiments described in Figures 8 and 9.

Received February 7, 2007; accepted May 24, 2007; published June 15, 2007.

\section{LITERATURE CITED}

Andrews JH, Harris RF (2000) The ecology and biogeography of microorganisms on plant surfaces. Annu Rev Phytopathol 38: 145-180

Bennett NR, Wallsgrove RM (1994) Transley review no. 72: secondary metabolites in plant defence mechanisms. New Phytol 127: 617-633

Hare JD (2005) Biological activity of acyl glucose esters from Datura wrightii glandular trichomes against three native insect herbivores. J Chem Ecol 31: 1475-1491

Hirano SS, Upper CD (2000) Bacteria in the leaf ecosystem with emphasis on Pseudomonas syringae: a pathogen, ice nucleus, and epiphyte. Microbiol Mol Biol Rev 64: 375-383

Jackson DM, Danehower DA (1996) Integrated case study: nicotiana leafsurface components and their effects on insect pests and diseases. In $\mathrm{G}$ Kerstiens, ed, Plant Cuticles. BIOS Scientific Publishers Ltd., Oxford, pp 231-254

Kelsey RG, Reynolds GW, Rodriguez E (1984) The chemistry of biologically active constituents secreted and stored in plant glandular trichomes. In E Rodriguez, PL Healey, I Mehta, eds, Biology and Chemistry of Plant Trichomes. Plenum Press, New York, pp 187-240
Kessler A, Baldwin IT (2002) Plant responses to insect herbivory: the emerging molecular analysis. Annu Rev Plant Biol 53: 299-328

Lambais MR, Crowley DE, Cury JC, Bull RC, Rodrigues RR (2006) Bacterial diversity in tree canopies of the Atlantic forest. Science 312: 1917

Leveau JHJ (2006) Microbial communities in the phyllosphere. In $\mathrm{M}$ Riederer, C Muller, eds, Biology of the Plant Cuticle. Blackwell Publishing, Boston, pp 334-367

Lindow SE, Brandl MT (2003) Microbiology of the phyllosphere. Appl Environ Microbiol 69: 1875-1883

Pfaffl MW (2001) A new mathematical model for relative quantification in real-time RT-PCR. Nucleic Acids Res 29: 2001-2007

Phillips MA, Croteau RB (1999) Resin-based defenses in conifers. Trends Plant Sci 4: 184-190

Shepherd RW, Bass WT, Houtz RL, Wagner GJ (2005) Phylloplanins of tobacco are defensive proteins deployed on aerial surfaces by short glandular trichomes. Plant Cell 17: 1851-1861

Shepherd RW, Wagner GJ (2007) Phylloplane proteins: emerging defenses at the aerial frontline. Trends Plant Sci 12: 51-56

Spring O, Rodon U, Macias FA (1992) Sesquiterpenes from noncapitate glandular trichomes of Helianthus annuus. Phytochemistry 31: 1541-1544

Svircev AM, McKeen WE, Smith RJ (1989) Host-parasite relations: morphology and ultrastructure. In WE McKeen, ed, Blue Mold of Tobacco. APS Press, St. Paul, pp 43-104

Wagner GJ, Wang E, Shepherd RW (2004) New approaches for studying and exploiting an old protuberance, the plant trichome. Ann Bot (Lond) 93: $3-11$

Wang E, Wagner GJ (2003) Elucidation of the functions of genes central to diterpene metabolism in tobacco trichomes using posttranscriptional gene silencing. Planta 216: 686-691

Watson JM, Fusaro AF, Wang M, Waterhouse PM (2005) RNA silencing platforms in plants. FEBS Lett 579: 5982-5987

Zasloff M (1987) Magainins, a class of antimicrobial peptides from Xenopus skin: isolation, characterization of two active forms, and partial cDNA sequence of a precursor. Proc Natl Acad Sci USA 84: 5449-5453

Zasloff M (2002) Antimicrobial peptides of multicellular organisms. Nature (Lond) 415: 389-395 